\title{
f12 cut in dental spending per person since 2010
}

Government spending on dental care per person in England has fallen significantly, according to figures recently unveiled in Parliament.

Responses ${ }^{1}$ to Parliamentary Questions raised by Peter Dowd, Labour MP for Bootle, showed that the equivalent of $£ 41.83$ per head was set aside by Government to cover dental care for every adult and child in England at the outset of the Coalition Government in 2010, which fell by more than $£ 12$ in real terms in $2017-18$ to $£ 29.69$ - effectively a $29 \%$ fall over the period.

The BDA said the figures, mentioned by Health Minister with responsibility for dental care Steve Brine on 5 February 2019 showed the full scale of cuts to NHS dentistry in England.

The trade union said the current funding arrangements were 'cuts by stealth' and were driving a 'do more with less' mentality to breaking point thanks to budgets failing to keep pace with inflation and population growth of three million.

As state contributions had fallen, patients had been asked to contribute ever more through NHS charges, said the BDA, highlighting the fact that charge levels have increased by more than $30 \%$ since 2010 , and now accounted for almost $30 \%$ of the total budget for NHS dentistry.

Dentistry had not received any of the NHS70 investment, and barely featured in the NHS Long Term Plan ${ }^{2}$ published in January 2019, said the union. Access and staffing problems had become endemic, with BDA surveys indicating that almost $60 \%$ of dentists were planning on reducing their commitment or leaving the NHS entirely in the next five years.

BDA Chair of General Dental Practice Henrik Overgaard-Nielsen said: 'There can be no rose tinting the fact more than $£ 12$ has been taken away from the dental care of every man, woman and child in England since 2010.
'These are cuts by stealth, and the public are paying for them through higher charges and longer waiting times. We've heard fine speeches about investment and prevention, but for NHS dentists the reality of 'do more with less' is being stretched to breaking point. And patients across England are seeing the result.

'A sustainable service cannot be built on sand. Every penny taken away from dentistry means pain left untreated and preventable conditions left to fester. It's a false economy that only piles further pressure on our NHS.'

\section{References}

1. House of Commons. Dental Services: Expenditure: Written question - 213397. 2019. Available at https://www.parliament.uk/business/publications/ written-questions-answers-statements/written-question/Commons/2019-01-28/213397/ (accessed February 2019)

2. Department of Health \& Social Care. The NHS Long Term Plan. 2019. Available at https://www. longtermplan.nhs.uk/publication/nhs-long-term-plan/ (accessed February 2019).

\section{Dentists treated more harshly by GDC without legal representation}

\begin{abstract}
Dentists who have to appear at hearings before the General Dental Council (GDC) tend to receive tougher sanctions if they do not have legal representation, it has been revealed.
\end{abstract}

Defence body Dental Protection submitted a Freedom of Information (FOI) request to the GDC on the issue of dental professionals and how they were treated with or without dento-legal support.

Results showed that almost two-thirds $(63 \%)$ of dentists erased from the register following a GDC hearing in 2018 did not have any legal representation.

In contrast, nine in ten dentists (92\%) found not to be impaired in their Fitness to Practise (FTP) had legal representation when they appeared before the GDC.

These professionals continued to practise without any sanction.

Dental Protection said the data underlined the need for dentists and the dental team to be supported by a dental defence organisation that would protect their interests before the GDC.

It said it regularly defended members on a wide range of matters, providing support from experienced dento-legal consultants and representation from lawyers specialising in supporting members in FTP cases as well as helping members on different matters including personal conduct matters at GDC hearings.

It was not unusual for the cost of defending a dentist at a hearing to amount to just under $£ 100,000$ when a GDC investigation led to a hearing, said the organisation.

Having specialist legal representation was important at all stages of an investigation and not just for the hearing, it argued, saying early engagement with Dental Protection advisers could mean that hearings or warnings, could be avoided, possibly involving bringing legal proceedings against the GDC on behalf of a member.

In 2018, for example, Dental Protection said it had brought Judicial Review proceedings against the GDC's decision to issue a warning to a Dental Protection member who had committed a minor driving offence. In this case, Dental Protection successfully argued that a GDC warning would be a disproportionate and unfair sanction by the regulator in these circumstances.

Raj Rattan, Dental Director at Dental Protection, said: 'These figures released by the GDC show just how important it is to have a good defence team if you are the subject of a GDC investigation. Dental Protection regularly supports dentists before the GDC and we know how disturbing it can be.

'The investigation process can be lengthy and very distressing for dentists who fear that their reputation and professional livelihood can be at stake. This is the reason why we support dentists throughout all stages of a GDC investigation. 